\title{
THORACIC INTERVERTEBRAL DISC PROLAPSE WITH SPINAL CORD COMPRESSION
}

\author{
BY \\ VALENTINE LOGUE \\ From the Neurosurgical Departments of St. George's Hospital, London, \\ and the Maida Vale Hospital for Nervous Diseases, London
}

The serious disorders of nervous function which may result from central protrusions of the intervertebral disc are exemplified in the thoracic region of the spine where this type of prolapse has acquired a sinister reputation, and the few cases treated by operation that have so far been reported bear witness to the severe damage that these protrusions inflict on the spinal cord and to the grave hazards attending their surgical removal. Thus, of Müller's (1951) four cases, three were left after operation with a complete or almost complete transection of the cord, and the fourth after a slight temporary improvement also developed a total paraplegia. Of Hawk's (1936) three patients who survived operation, all with severe pre-operative spinal cord damage, one was made worse by, and the other two showed no benefit from, surgery. Mixter and Barr (1934) reported three cases, two of which developed a total transverse lesion and the third eventually showed slight improvement. So of 10 cases of central thoracic disc prolapse treated surgically, six were left with virtually complete cord transection and there was little or no worthwhile improvement in the other four, a unique morbidity rate among benign compression lesions of the cord.

It is my purpose to describe a series of 11 cases all proven by operation which does to some extent confirm this grave picture, but also reveals that it is possible to make an accurate pre-operative diagnosis of this type of herniation and to remove a certain number of these protruding discs not only without further damage to the spinal cord but with almost complete restitution of neurological function.

\section{Incidence}

These 11 cases have appeared in a modest total of 250 disc protrusions at all levels, an incidence of $4 \%$ for thoracic prolapse, which is a greatly exaggerated one owing to the restricted choice of cases for admission ; the true proportion is probably in the neighbourhood of two or three per 1,000 disc prolapses as reckoned by Love and Kiefer (1950) in the cases at the Mayo Clinic. It is of interest that among these 250 cases there were also 14 patients with central lumbar disc protrusions producing cauda equina compression and 15 central cervical protrusions with spinal cord involvement.

\section{Site}

There are 12 thoracic intervertebral discs, the first lying between the first and second thoracic vertebrae and the twelfth between the last thoracic and first lumbar vertebrae, and the portion of the spinal cord which is exposed to compression by central protrusions of these discs extends from the third thoracic to the fifth lumbar spinal segment.

Fig. 1 shows the disc levels at which the protrusions

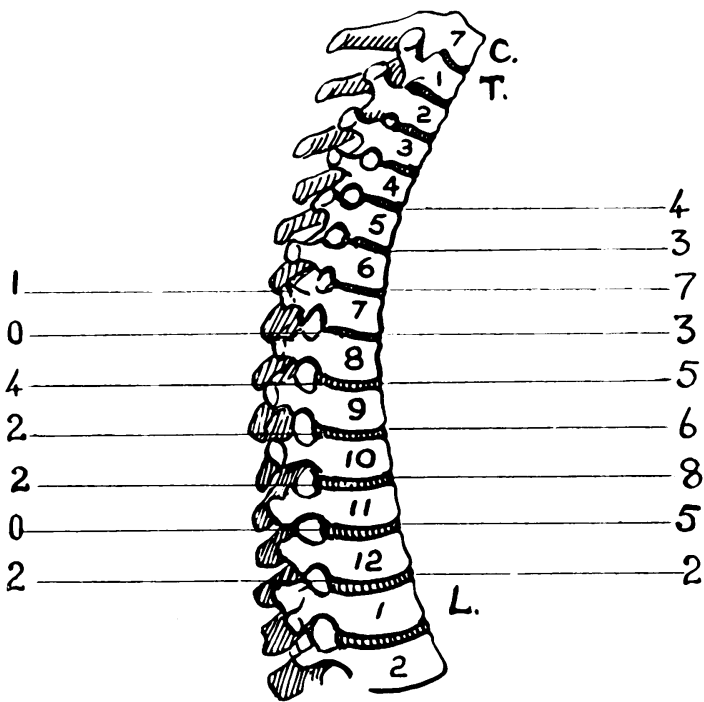

Fig. 1.-The figures on the left refer to the 11 cases in this series. The list of 43 on the right includes an additional 32 reported cases: Bradford and Spurling (1945) one; Elsberg (1931) two ; Hawk (1936) four; Love and Kiefer (1950) 17, including three of lateral disc protrusion; Mixter and Barr (1934) four cases; and Müller (1951) four cases. 
have occurred. The list on the left of the diagram refers to this series of 11 cases. To obtain a more accurate picture an additional 32 reported cases, verified by operation or necropsy, have been collected making a combined total of 43 , which is shown in the list to the right of the diagram. This demonstrates that central protrusions are confined to the lower nine intervertebral discs without, however, a predilection for any two of them as pertains in the lumbar and cervical regions.

\section{Sex, Age, and Trauma}

Table I shows that there are nine men and two women in the series, in accord with the general rule that disc protrusions at any level tend to be more common in males. This predominance is confirmed, but on a lesser scale, by the larger group of 43 cases in which the ratio is as five to three. It is also apparent from this table that thoracic disc prolapse is a disease of middle and late adult life, the youngest patient being 38 years old and the average age of the whole series 50 years.

TABLE I

SEX, AGE, AND INCIDENCE OF TRAUMA IN 11 CASES

\begin{tabular}{c|c|c|c}
\hline $\begin{array}{c}\text { Case } \\
\text { No. }\end{array}$ & Sex & Age & $\begin{array}{c}\text { History of } \\
\text { Trauma }\end{array}$ \\
\cline { 1 - 2 } 1 & Male & 48 & Yes \\
2 & Male & 44 & No \\
3 & Male & 38 & Yes \\
4 & Male & 52 & No \\
5 & Male & 62 & No \\
6 & Female & 44 & Yo \\
7 & Female & 63 & No \\
8 & Male & 54 & No \\
9 & Male & 61 & No \\
10 & Male & 44 & No \\
11 & Male & 45 & \\
\hline
\end{tabular}

Direct or indirect trauma plays little part in the aetiology of prolapse in this region of the spine. In only three of these patients was there any possible association with injury. In one patient (Case 1) the first symptom of back pain, which preceded the onset of neurological signs by 10 years, appeared while he was lifting some heavy weights. In the second (Case 3) back pain appeared a few days after an episode of vigorous gardening and was followed five months later by cord compression. The third patient (Case 7) twisted her back while turning suddenly and her first symptoms appeared next day. In the remaining eight cases there was no history of injury or unusual exertion and the patients were otherwise in normal health.

\section{Clinical Features}

A description of the neurological findings in each of these patients appears in some detail in the case histories at the end of this paper. A study of them confirms what might have been expected; that there are no symptoms or signs which are characteristic of compression of the spinal cord by a thoracic disc prolapse and that they do not differ materially from those produced by spinal neoplasms. The following case illustrates some of the common clinical features of the condition and also the pitfalls that may beset the diagnosis in the early stages.

Case 11. - A man aged 45, a research chemist, seven months before admission developed pain in his back at about the dorsi-lumbar junction, slightly to the left of the midline. It was intermittent, had an aching character, and was made worse when lying down, but was unaffected by coughing and straining. He had sustained no injury to his spine.

A few days later numbness appeared in the right thigh and quickly spread down the leg to the toes and upwards to the level of the umbilicus. Two weeks later the right leg became stiff, weak, and unreliable so that he tended to fall. He was investigated at another hospital two months after the onset of symptoms and was found to have a spastic right leg with increased reflexes in both legs and a right extensor plantar response. There was patchy impairment of sensation to pain and light touch over the right leg and the inner side of the left ankle. Lumbar puncture at that time showed no evidence of spinal block and the fluid contained three cells and $25 \mathrm{mg}$. \% of protein. He was thought to be suffering from atypical disseminated sclerosis and was sent home. His symptoms progressed steadily and five months after the onset weakness and numbness appeared in the left leg and he also developed urgency of micturition and difficulty in defaecation.

Neurological Examination.-There was a little weakness in the lower abdominal muscles and considerable weakness of both legs with increased tone, more marked on the right, and sustained ankle clonus. Coordination was grossly impaired.

The abdominal reflexes were absent. The knee and ankle jerks were exaggerated, more so on the right. Both plantar responses were extensor.

There was a level at the seventh thoracic dermatome on both sides below which there was some impairment of pain sense and a more definite level at the tenth dermatome below which there was considerable impairment to pain, light touch, and temperature, but not complete loss. Position sense was absent at the toes and reduced at the ankles. Vibration sense was absent over the right tibia and reduced on the left.

He was just able to walk without support, but very unsteadily on a wide base.

He was later proved to have a prolapse from the ninth-tenth intervertebral disc. (The details of investigation are described at the end of this paper.)

In general the symptoms of cord compression appeared in the chronological order of sensory 
(pain, tingling, burning, coldness, or numbness), motor, and sphincter, and once begun the course was that of a relentless and fairly rapid progression so that in eight of the 11 cases the time elapsing from the first symptom of compression to the development of a marked neurological deficit warranting surgery was less than seven months. As exceptions to this rule there were three cases (Nos. 6, 4, and 7) with histories of 14 months, two years, and 10 years respectively, and in the last of these the course did show some remittent features.

Among the first group of eight cases there were three (Cases 5, 8, 9), and these will be referred to again when dealing with the mechanics of compression, in which the symptoms of a severe paraplegia developed acutely in the course of several days, but in only one (Case 9) was a recent soft disc prolapse found at operation. In the other two cases the protrusion was bony hard and had obviously been present for a considerable time, probably years, and the sudden appearance of a paraplegia was thought to be due to interference with the blood supply to the cord.

In most of the patients the symptoms started in both legs at the same time, or if they did appear first in one leg the other was soon involved, so that by the time of admission to hospital neurological examination revealed signs indicative of compression of both halves of the spinal cord. In three patients, however (Cases 1, 2, 3), the presenting neurological picture was that of a Brown-Séquard syndrome, resulting from compression of one half of the spinal cord by a prolapse situated just to one side of the midline of the spinal canal. That protruded cervical discs could cause either bilateral or strictly unilateral cord compression was noted some years ago by Stookey (1928) and in practice this distinction is not as artificial as it may at first appear. This observation of Stookey's also holds true for the thoracic region, but here the hemicompression syndromes are proportionately less frequent and not so clearly defined as with cervical protrusions because of the larger size of the thoracic prolapse relative to the smaller bulk of the spinal cord in this region. In the three representative cases mentioned above the syndromes are by no means complete.

In the sensory field, as would be expected with an anteriorly situated lesion, pain and temperature sense were more affected than light touch and the modalities subserved by the posterior columns; in fact in some cases the latter structures were practically uninvolved.

One patient (Case 11) showed sensory impairment extending up to a dermatome level considerably higher (four segments) than that of the spinal segment actually under compression and gave rise to some confusion in localization. This phenomenon has been previously noted in thoracic prolapse (Hawk, 1936) and is of course well recognized, although not satisfactorily explained, in association with spinal neoplasm and in cervical disc prolapse.

Sphincter disturbance was not a prominent symptom and, except for one case, when it did occur it appeared late in the course of the compression. In six patients there were no bladder or rectal disturbances whatsoever, often despite severe weakness of the legs. In three cases there was mild urgency or dribbling on micturition, and in only two cases, both with gross paraplegia, was there loss of sphincter control (Cases 7 and 10).

\section{Pain}

A feature of central disc prolapse which is common to the cervical and thoracic regions is the inconstant association of pain, either local or radicular. In nearly half of these cases (five out of 11) there was no complaint of pain at any time in the evolution of the clinical picture. Of the six patients who did experience pain, four (Cases 1, 3, 9 , and 11) felt it locally in the back, where it preceded the onset of cord symptoms by a variable time ranging in the individual case from a few hours to 10 years. The pain was felt in the midline of the spine, sometimes extending a little to one side, and was located in the upper lumbar or thoraco-lumbar regions irrespective of the level of the prolapse. It was usually described as having an aching character, was not particularly severe, and often occurred in attacks similar to lumbar disc pain. In the remaining two patients (Cases 5 and 8 ) the prolapse was at the D.12/L.1 level and nerve root pain was produced which had a characteristic distribution extending from the upper lumbar region down the front and back of each lower limb as far as the ankle, but predominating in the anterior aspect of the thighs. This radiation was explained by the location of the prolapse where it was anatomically possible for it to involve the majority of the lumbar and also the upper sacral nerve roots as they lie closely grouped together round the conus medullaris.

\section{Investigations}

Changes in the Cerebrospinal Fluid.-Table II illustrates the degree of block on manometry and the protein content of the cerebrospinal fluid in the 11 cases. Five of the patients had a complete or almost complete spinal manometric block with, in the four cases in which it was recorded, considerable 
TABLE II

MANOMETRIC CHANGES AND PROTEIN CONTENT OF CEREBROSPINAL FLUID

\begin{tabular}{c|l|l}
\hline $\begin{array}{c}\text { Case } \\
\text { No. }\end{array}$ & \multicolumn{1}{|c|}{$\begin{array}{c}\text { Manometric } \\
\text { Results }\end{array}$} & $\begin{array}{l}\text { Protein Content of C.S.F. } \\
\text { (mg. per 100 ml.) }\end{array}$ \\
\hline 1 & $\begin{array}{l}\text { No block } \\
\text { No block }\end{array}$ & 55 \\
2 & Partial block & Not recorded \\
3 & Complete block & 30 Yellow fluid ; protein \\
4 & Complete block & Yellow fluid 175 recorded \\
5 & Complete block & 95 \\
6 & Complete block & 150 \\
7 & Almost complete block & 200 \\
8 & Partial block & 100 \\
9 & Partial block & 20 \\
10 & No block & 50 \\
\hline
\end{tabular}

elevation of the protein content of the cerebrospinal fluid to $200,175,150$, and $95 \mathrm{mg}$. per $100 \mathrm{ml}$. respectively. A partial block or "sticky" manometrics was recorded in three patients (Cases 9, 3, and 10 ) with a protein content of 100,20 , and $30 \mathrm{mg}$. per $100 \mathrm{ml}$. In the remaining three cases there was no evidence of block and the cerebrospinal fluid protein was 55 and $50 \mathrm{mg}$. per $100 \mathrm{ml}$. respectively in the two cases in which it was recorded.

It should also be noted that in two of the patients (Cases 4 and 11) both the cerebrospinal fluid and the hydro-dynamics were completely normal at a time when considerable neurological damage was present. The former patient went on to develop a total spinal block a year later and removal of the disc at that stage aggravated the paraplegia.

Perhaps the important deduction from these findings is not that thoracic disc prolapse can cause a complete spinal block but that in the early stages of the condition the manometrics and cerebrospinal fluid may be entirely normal, and even in the later stages of gross neurological disability there may be at most a partial block or a slight increase in the protein content.

Radiology.-In contrast to the clinical features of prolapsed thoracic discs, which are of little value in positive diagnosis, some of the radiographic changes form a reliable guide, and it should be possible by this means to make a pre-operative diagnosis in the majority of cases.

Arthritic lipping of the vertebral bodies in the thoracic spine, and often in the lumbar region as well, is frequently seen in these patients but appears to be no more common or more extensive than that observed in patients of this age group without disc prolapse. Narrowing of the affected disc was not a constant feature and in fact was often seen in discs which had not protruded.

With regard to calcification of the nucleus pulposus, however, it is an entirely different story.
Of these 11 cases of thoracic prolapse, no less than eight showed unequivocal calcification in a nucleus pulposus. The significance of this finding was brought out by a study of the radiographs of the thoracic spine of 100 cases of similar age group who had had radiographs taken because of local spinal symptoms resulting from injury, arthritis, etc., and in which nuclear calcification was observed in only four instances compared with an incidence of over $70 \%$ with disc prolapse.

Again, in 25 patients suffering from thoracic spinal compression by neoplasms such as neurofibromata, meningiomata, and metastasic tumours, drawn from a similar age group, there were no instances of nuclear calcification.

The calcified disc, however, is not necessarily strictly related to the level of the prolapse. Table III

\section{TABLE III}

INTERVERTEBRAL DISC LEVEL OF CALCIFICATION, RELATIONSHIP TO THE SITE OF PROLAPSE, AND MYELOGRAPHIC APPEARANCES

\begin{tabular}{|c|c|c|c|}
\hline $\begin{array}{l}\text { Case } \\
\text { No. }\end{array}$ & \begin{tabular}{|c|} 
Level of Disc \\
Prolapse
\end{tabular} & $\begin{array}{c}\text { Level of } \\
\text { Calcification }\end{array}$ & $\begin{array}{l}\text { Myelographic } \\
\text { Appearances }\end{array}$ \\
\hline $\begin{array}{l}1 \\
2 \\
3 \\
4 \\
5 \\
6\end{array}$ & $\begin{array}{lr}\text { D } & 9 / 10 \\
\text { D } & 8 / 9 \\
\text { D } & 8 / 9 \\
\text { D } & 6 / 7 \\
\text { D } & 12 / 1 \\
\text { D } & 8 / 9\end{array}$ & $\begin{array}{l}\text { D } 9 / 10 \\
\text { D } 8 / 9 \\
\text { D } 8 / 9 \text { and } 9 / 10 \\
\text { D } 6 / 7 \\
\text { D } 8 / 9 \\
\text { D } 8 / 9\end{array}$ & $\begin{array}{l}\text { Oval defect } 2 \times 1.5 \mathrm{~cm} \text {. } \\
\text { Partial block } \\
\text { Oval filling defect } \\
\text { Complete block } \\
\text { Complete block } \\
\text { Circular filling defect }\end{array}$ \\
\hline $\begin{array}{r}7 \\
8 \\
9 \\
10\end{array}$ & $\begin{array}{l}\text { D } 10 / 11 \\
\text { D } 12 / 1 \\
\text { D } 10 / 11 \\
\text { D } 8 / 9\end{array}$ & $\begin{array}{l}\text { No calcification } \\
\text { No calcification } \\
\text { No calcification } \\
\text { D } 8 / 9 \\
\text { D } 9 / 10 \\
\text { D } 10 / 11 \\
\text { D } 11 / 12 \\
\text { D } 9 / 10\end{array}$ & $\begin{array}{l}\text { Partial block } \\
\text { Complete block } \\
\text { Complete block } \\
\text { 二 } \\
\text { Partial block } \\
\text { Oval flling } \\
2 \times 1.5 \mathrm{~cm} .\end{array}$ \\
\hline
\end{tabular}

shows that in five of these eight patients the calcification occurred only in the nucleus pulposus of the disc which had actually herniated. In two other patients there were several calcified discs (Cases 2 and 4 respectively) of which one in each case corresponded to the site of the prolapse. In the final case the calcification was present in a single nucleus but this was situated four disc spaces above the protrusion. It would seem that nuclear calcification in the thoracic region is indicative of a degenerative change of such a nature as to render the disc liable to prolapse, but this change may also be present in other discs as yet uncalcified, and it may happen that prolapse occurs from one of the latter.

In a person suffering from spinal cord compression in the thoracic region calcification of a nucleus pulposus is an important finding, and as a general guide it may be stated that if the segmental level of the lesion corresponds with a calcified 
nucleus then the diagnosis of a protruded disc is practically certain, and even when the segmental level does not correspond a herniation is still the most likely diagnosis.

The calcification is best seen in the lateral view. Its appearance in the nucleus has no specific features and, as Figs. 2, 3, and 4 demonstrate, it varies considerably. It may consist of a uniformly dense plaque which occupies part or the whole of the nucleus (Fig. 2) or it may be arranged in the form of flakes or granules (Figs. 3 and 4).

At operation the periphery of some of the protrusions was found to be quite heavily calcified, but it has been possible in only one (Case 6 and Fig. 5) to demonstrate this circular rim by radiography. In the others the shadow was presumably too faint to be discerned amid the dense bone in the vicinity.

Myelography.-The thoracic region is notoriously difficult to screen, partly owing to the superimposed shadows of the heart and great vessels which tend to obscure detail, and partly owing to the convexity of this portion of the spinal column, which is accentuated in these older patients. As soon as the contrast material runs over the thoracic hump whether going up or down the spinal canal it tends to glide rapidly over the remaining vertebrae to gain the lordosis of the lumbar or cervical regions, often breaking up into globules as it does so, and during this rapid flow it is possible to overlook the small filling defects which may be the only sign of a thoracic prolapse.

Table III shows that on myelographic screening of these 11 cases four showed a complete block which often had a convex border to it (Fig. 6 and Case 9). Of the remaining seven, three revealed a partial block without characteristic features and in four the only evidence of a disc was a filling defect in the column of contrast material. This filling defect has quite typical features (Fig. 7). It is circular or oval in shape, varying from 1.5 to $2 \mathrm{~cm}$. in diameter, and overlies the intervertebral disc space and adjacent portions of the vertebral bodies. If good lateral views can be obtained (and this is of ten very difficult) it is usually possible to demonstrate that the obstruction lies anteriorly.

In two of the patients (Cases 3 and 8) in the lateral view of the myelogram a "double profile" could be seen at the level of the affected disc (Fig. 8 ), an appearance which depends on the prolapse being situated to one side of the midline so that part of the contrast medium runs over the convexity of the prolapse and part runs in the dural gutter alongside it, giving two levels which may be as much as a centimetre apart.

\section{Mechanics of Spinal Cord Compression}

It is pertinent at this stage to enquire briefly into the means whereby the herniated disc produces interference with cord function. In some cases there is manifestly a true compression as a result of the large size of the protrusion which may occupy the greater part of the diameter of the spinal canal and squeeze the cord backwards against the lamina and ligamentum flavum. In other cases, however, the prolapse may be relatively small and incapable of " compressing" the cord as a whole, and another explanation has to be sought. This problem has previously arisen with regard to cervical disc lesions, and two explanations have been put forward. One concerns the ligamenta denticulata and the other the blood supply to the spinal cord.

Kahn (1947) made the suggestion that the ligamenta denticulata resisted the backward displacement of the cord and produced traction on, and distortion of, the nerve fibres in the vicinity of the attachment of the ligaments to the transverse meridian of the cord. This may well be the explanation of the neurological signs in some of the cervical disc compressions, particularly in those cases which present with almost exclusive involvement of the pyramidal tracts.

In some cases of thoracic (and cervical) disc compressions, however, it has been proposed that interference with the blood supply is the basis of the pathological change, in particular as a result of obstruction or occlusion of the main arterial trunk - the anterior spinal artery. This would best explain (1) the appearance of a neurological picture resembling that which occurs in known cases of anterior spinal arterial thrombosis ; (2) the abrupt onset in some patients of extensive damage to the cord when at operation a hard prolapse evidently of very long standing is found; (3) the occurrence of degenerative changes amounting to necrosis of the cord substance; and (4) the severe damage inflicted on the cord out of all proportion to the size of the protrusion, and the poor recovery that may result despite the complete removal of the prolapse.

It was therefore with the hope that some light would be thrown on this problem that the spinal cord in the one patient coming to necropsy (Case 6) was examined, but it was clearly shown in this case that there were no demonstrable changes in the main vessel which could be invoked as the cause of the neurological picture or of the post-operative transverse lesion.

The patient had a 14-month history of progressive paraplegia and developed a total transverse 


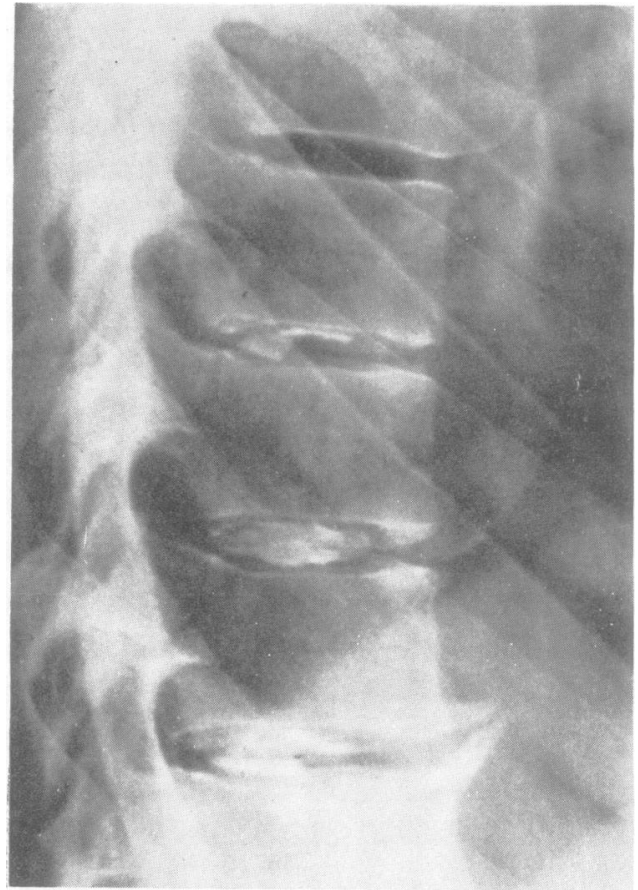

FIG. 2.-Lateral radiograph of the thoracic spine in Case 10 showing the dense calcification in the nucleus pulposus of three of the four calcified discs.

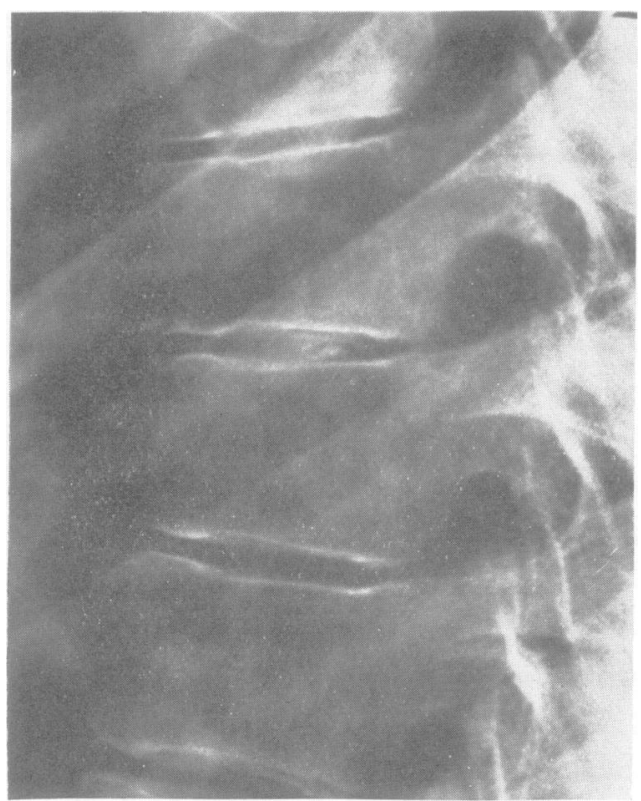

FIG. 4.-Lateral radiograph of Case 6 showing the granular appearance of the calcification in the nucleus of the eighth-ninth intervertebral disc.

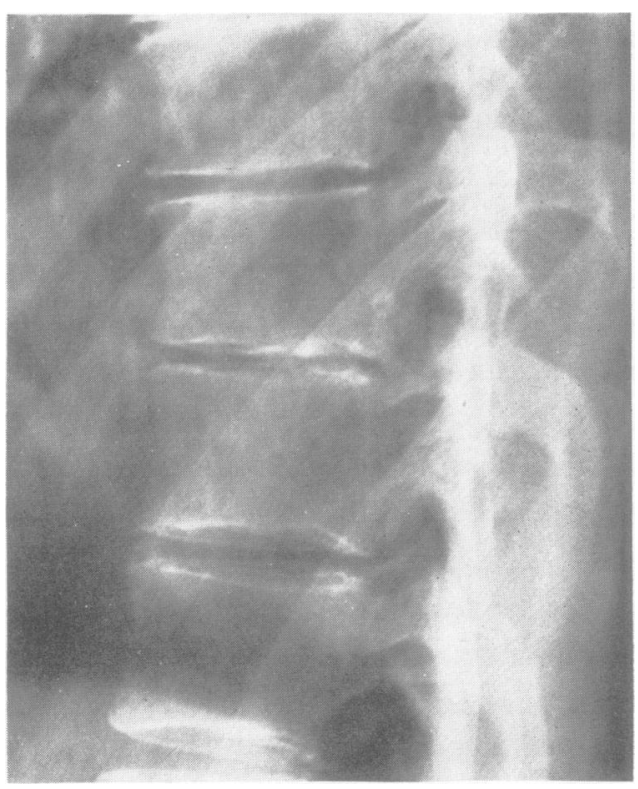

Fig. 3.-Lateral radiograph of Case 11. Flaky calcification is present in the nucleus pulposus of the ninth-tenth intervertebral disc.
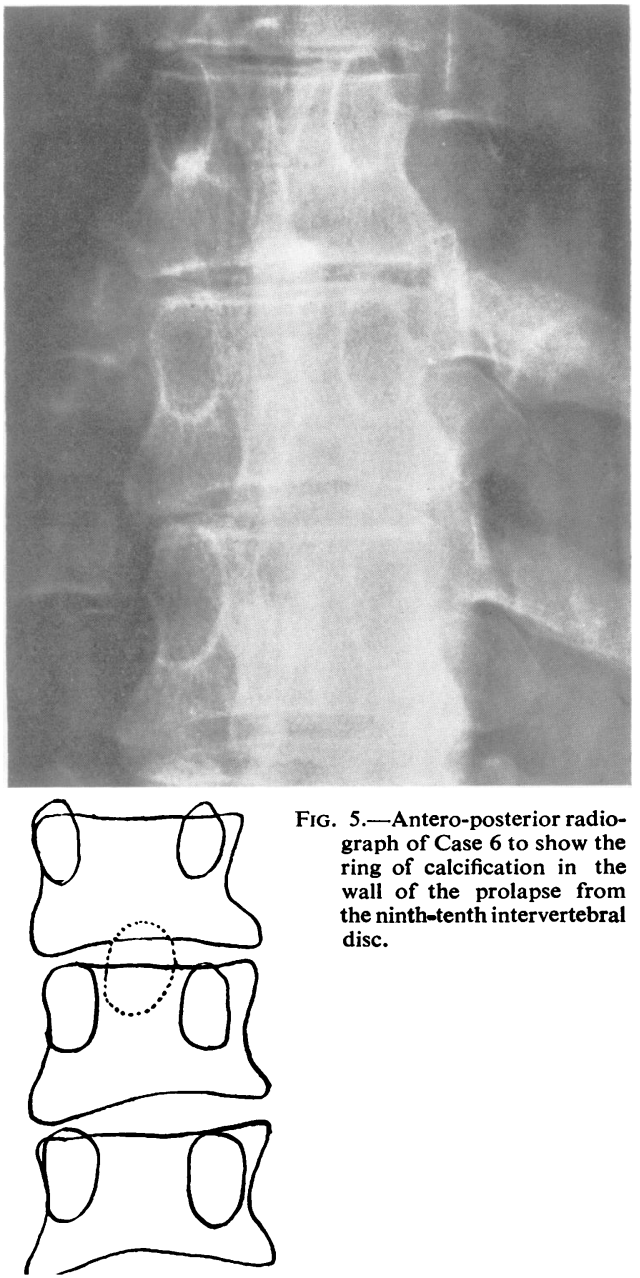

FIG. 5.-Antero-posterior radiograph of Case 6 to show the ring of calcification in the wall of the prolapse from the ninth-tenth intervertebral disc. 


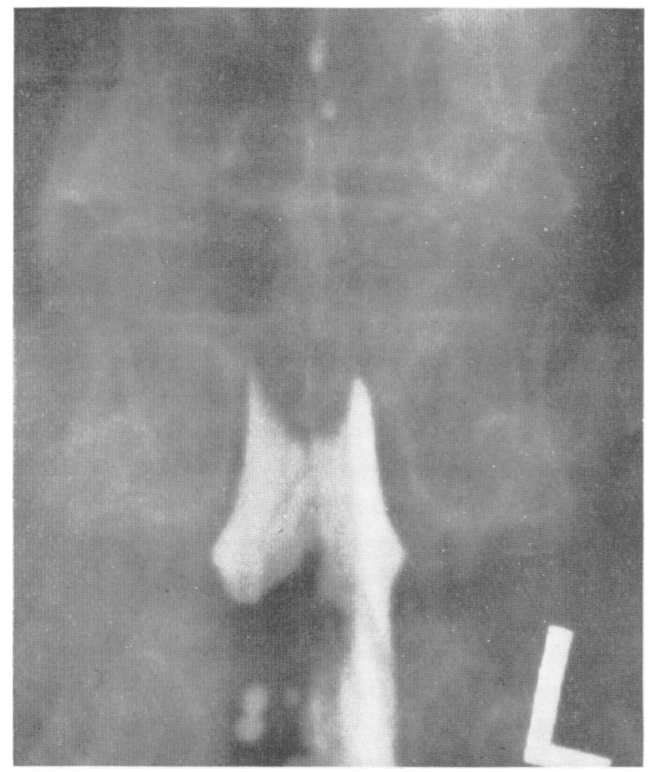

FIG. 6.-Myelogram of Case 9 illustrating the complete obstruction just below the tenth-eleventh disc with a convex lower border. It was similarly outlined from above.

lesion after operation, succumbing nine months later. The spinal cord, dura, and prolapse were removed in one piece and then sectioned en bloc (Fig. 9). The extreme distortion of the fibre tracts is well shown but the anterior spinal artery, although in close apposition to the prolapse, is quite patent without any thickening of its wall, and this appearance was confirmed at higher and lower levels. The anterior spinal vein also showed no evidence of damage.

\section{Surgical Results}

The results of surgery in these cases are not such as to foster complacency. There were in all five bad results (Cases 2, 4, 5, 6, and 7) and two of these patients died.

Of these five patients, three (Cases 5, 6, and 7), all severely disabled before operation, developed a total transection post-operatively. One (Case 5) died four months later from urinary sepsis without having made any neurological improvement. Case 6 showed slight recovery in motor power and pain sensation and then died nine months after operation from urinary sepsis and bed-sores. The third patient (Case 7), who showed gross degenerative changes in the spinal cord at operation, has made no recovery in four years. The prolapse was excised completely in the first case but in the other two surgical intervention was confined to a decompression.

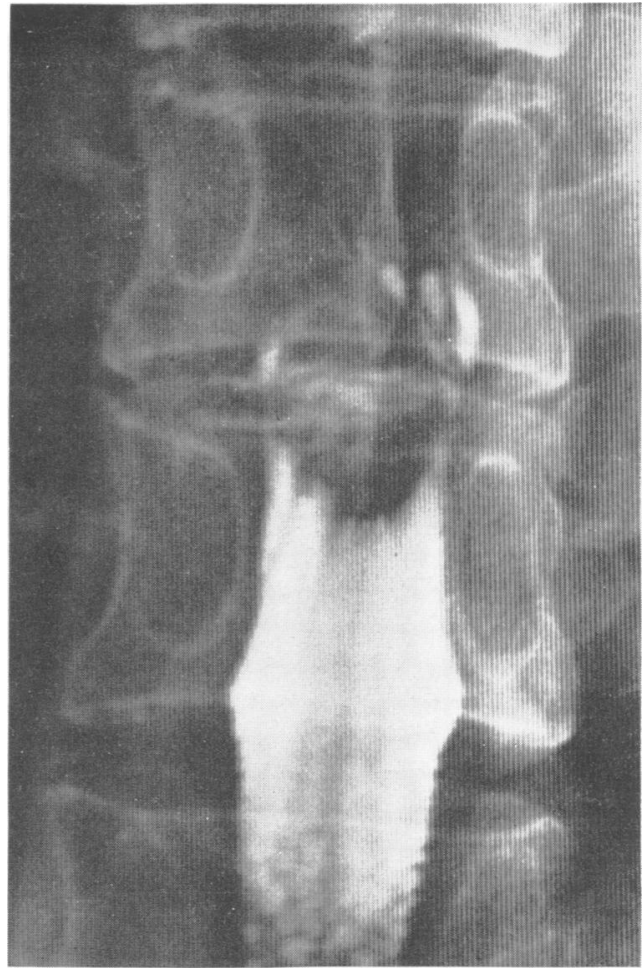

Fig. 7.-Myelogram of Case 11 showing the typical oval filling defect at the level of the calcified disc (D 9/10).

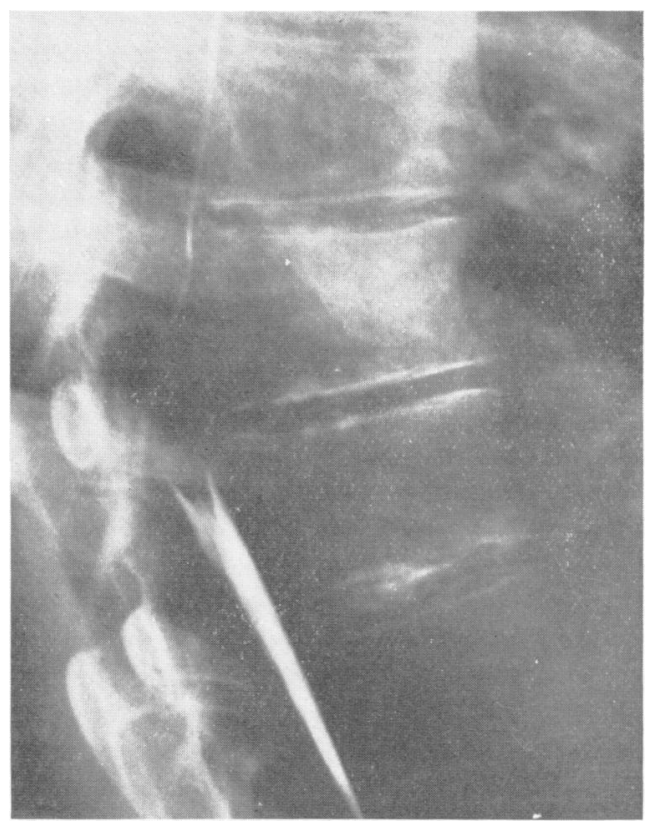

FIG. 8.-Lateral radiograph of the myelogram in Case 3. Calcification is present at the eighth-ninth and ninthtenth disc levels. The double profile of the contrast medium outlines the prolapse which has occurred from the upper, less calcified, disc. 


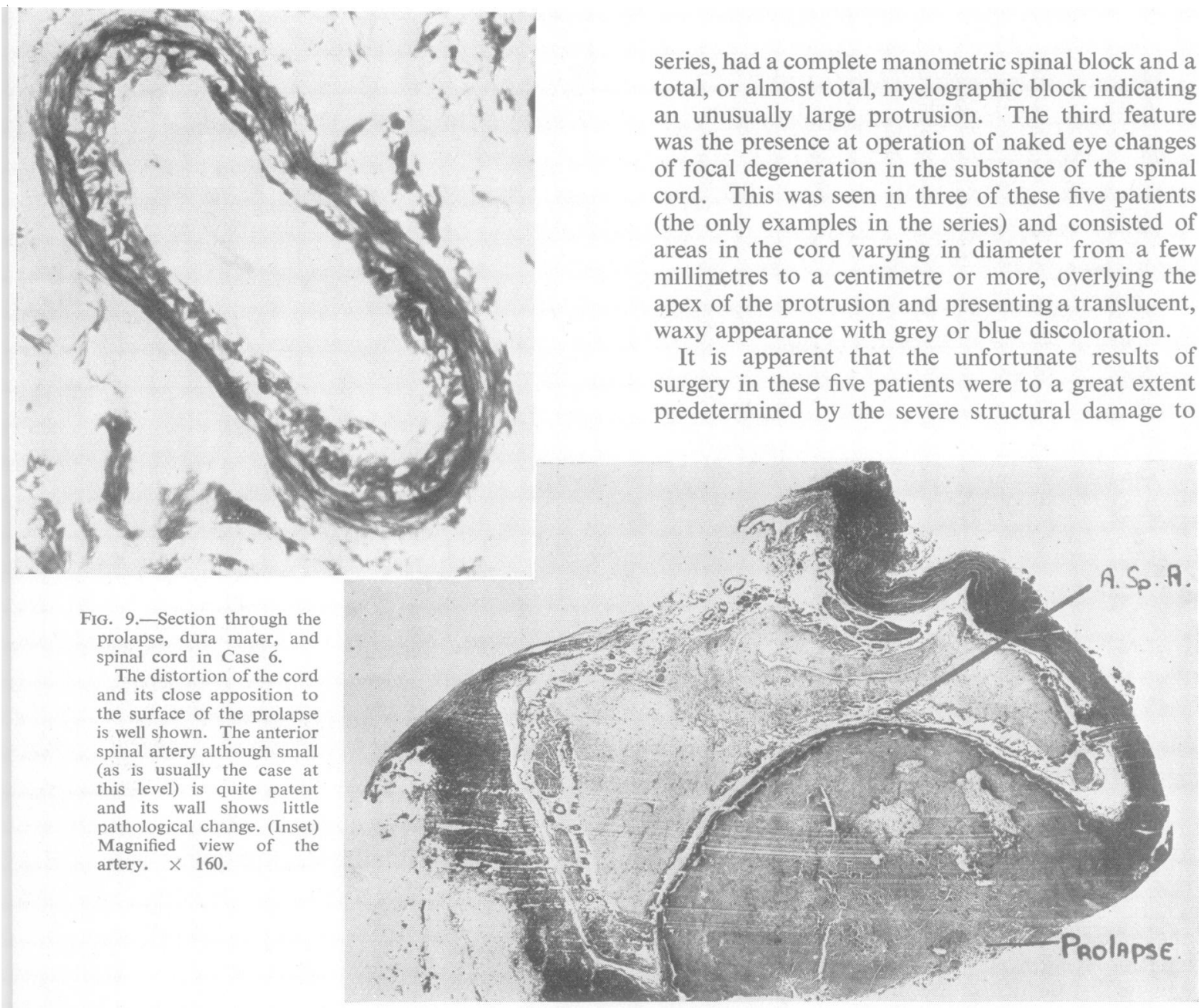

Two patients (Cases 2 and 4), both showing macroscopical degenerative changes in the cord substance at operation, and the latter with a severe pre-operative paraplegia, were rendered worse by removal of the protrusion and then made slow, incomplete recoveries over several years so that they were eventually able to get about with the aid of sticks. Six years after operation Case 4 again retrogressed to an almost total paraplegia, possibly from further protrusion of the disc.

Study of these five cases reveals that in addition to their tragic outcome they had several other features in common. The first of these was the severity of the neurological disability before operation; and four of these five patients had gross paraplegias at the time of admission to hospital. The second feature was the size of the compressing lesion, and again four of these cases, out of five in the whole

the spinal cord, as manifested by the severity of the neurological disability, the large size of the protrusion, and visible degenerative changes.

The remaining six patients present a happier picture.

Case 8. - This man had a severe paraplegia so that he was able to walk only a few steps and then with severe pain in the back and legs. Sensation was less affected. Surgery was limited to a decompression as the protrusion was of bony hardness. This procedure seems to have arrested the progress of the condition and there has been slight improvement in so far that he is able to get about his house in reasonable comfort and can walk distances up to 200 yards with a stick and stand for periods up to half-an-hour. Sphincter control is normal.

Case 1.-In this case there was evidence of a fairly severe Brown-Séquard syndrome. Most of the disc prolapse was excised ; this temporarily exacerbated the 
physical signs, but in the 12 months since operation he has made steady improvement. He is now able to walk distances up to two miles and has returned to work driving a van. Bladder control is practically normal and his original back pain, present for 10 years, has disappeared.

Case 10. - This patient was grossly disabled and was unable to lift his legs against gravity. There was dense sensory loss and retention of urine and faeces. A complete removal of the prolapse was carried out. It is now two and a half years since operation. He is able to walk 500 yards with the aid of sticks and has returned to full-time sedentary work. Some urgency of micturition persists but bowel control is normal.

Case 11. - This man had a similar but slightly less severe neurological deficit. The major part of this prolapse was removed but the right hand margin was inaccessible. It is now three and a half years since operation and for the last two and a half he has been back at full work and can walk and run normally, and drives a car. His only residual symptom is that of a sensation of cramp and tightness in the muscles of the left leg and subjective numbness of the feet.

Case 9.- This patient showed considerable motor weakness with milder posterior column sensory impairment as a result of an acute prolapse of softened nucleus pulposus, which was completely excised. At 10 months after operation he can walk any distance with one stick. He has no pain or sensory change and sphincter control is normal.

Case 3.-This was the youngest patient in the series and presented with a mild Brown-Séquard syndrome. The disc was totally excised. It is now three years since operation and for the last two and a half of them he has been back at full work, and can walk, run, dance, and dig as well as he ever did. His remaining symptoms are those of a sensation of tightness in the calves and some loss of potency.

This last case represents the best result obtained in this series and is perhaps accounted for by the short history of compression (two and a half months), a small prolapse, and the absence of degenerative change in the cord at operation.

\section{Surgical Management}

The surgery of compressing lesions which lie anterior to the spinal cord is never easy and is made immeasurably more difficult in disc prolapse by the changes produced in the cord which render it vulnerable even to the slightest surgical trauma. In addition the anatomical relationship of the cord to the protrusion (Fig. 9) makes access extremely difficult. The consistency of the prolapse is sometimes another hazard, for it may be composed of a small central area of cartilage set between bony spurs which project from the vertebrae above and below (Case 7), and which cannot be chiselled away without risk of further injury to the nervous structures. However, a recent report by Allen (1952) suggests that it is possible to remove these spurs by the technique he describes without increasing the damage to the cord, and it may be that a more radical attitude will be taken in the future.

In the surgical approach the most important factor is an accurate pre-operative diagnosis and the knowledge from the start that one is dealing with a discal hernia. This knowledge should ensure removal of the lamina with the utmost caution and so prevent any further compression of the cord against the unyielding prolapse during the exposure. Other technical points are : that the laminectomy should be extensive consisting of at least three, preferably four, laminae ; in a narrow spinal canal I have no hesitation in removing the pedicle on the side of the maximum protrusion to gain a more lateral approach; all the ligamenta denticulata in the operative field should be divided. It is perhaps hardly necessary to emphasize the extreme gentleness required in lifting up the edge of the spinal cord to gain access to the hernia, and for this reason it is best to remove the prolapse by the intradural route so that the minimal displacement of the cord that is permitted can be kept under direct control. The soft central area of the prolapse is usually easily removed but the hard rim may require to be excised piecemeal with a fine gouge.

Once the protrusion has been exposed a decision has to be made either to attempt its removal or to be content with a decompression with or without division of the ligamenta denticulata. If there is an area of necrosis in the cord, and this is a most ominous sign even when the associated neurological deficit is not severe (Case 2), a decompression is all that should be done. If the type of prolapse is that of the transverse bony spur it is again probably safer not to attempt a radical excision (but this view may require modification in the future). On the other hand, if the cord is not grossly abnormal and the prolapse has the more usual rounded, sometimes mushroom, shape it is imperative to remove it entirely for it is only by this means that any considerable recovery in neurological function can result.

It is evident that the reputation these central thoracic disc protrusions have acquired is not undeserved. It is only by early diagnosis before permanent changes occur in the spinal cord that an improvement in surgical results will be obtained, and this should be possible, if with a progressive thoracic spinal lesion the significance of a calcified nucleus pulposus is appreciated, and myelography with careful screening is undertaken at a stage when 
the manometrics and cerebrospinal fluid may well be normal.

\section{Case Histories}

The post-operative condition of the 11 patients is described mainly in terms of recovery of function and the finer details of neurological examination are omitted.

The first three cases are examples of incomplete Brown-Séquard syndromes.

Case 1.-A man aged 48, a greengrocer, four months before admission developed numb feeling in both legs followed in a few days by weakness, particularly in the left leg, which progressed steadily. He had no sphincter disturbance. Ten years previously, after lifting a heavy weight pain appeared in the upper lumbar region and had occurred intermittently ever since. It had an aching character, did not radiate, and was not severe, usually being relieved by the application of heat. He had also contracted syphilis 21 years previously for which he had received treatment at the time.

Neurological Examination.-There was generalized weakness of the left leg with increased tone but no clonus, and impaired coordination.

Reflexes were exaggerated with an extensor plantar response. In the right leg no abnormality of power, tone, or reflexes was discerned.

On the left side sensation was normal except for the absence of vibration sense over the tibia. On the right there was a sharply defined level at the twelfth thoracic dermatome below which there was impairment of pain, temperature, and light touch. Vibration sense was normal. The sense of position and passive movement was unaffected in both legs.

The patient could walk unaided, rather hesitantly, circumducting the left leg.

Radiography.-Radiography showed dense mottled calcification of the ninth-tenth nucleus pulposus without narrowing of the disc space and arthritic lipping of D.11 and 12 .

Myelography.-Myelography showed an oval filling defect 2 by $1.5 \mathrm{~cm}$. at the level of the calcified disc.

Lumbar Puncture.-Manometrics were normal. The fluid contained one cell per c.mm. and $55 \mathrm{mg}$. of protein per $100 \mathrm{ml}$. The Wassermann reaction was negative, and the Lange reaction unchanged.

Operation.-Laminectomy of the ninth, tenth, and eleventh thoracic vertebrae was performed. A firm swelling was felt anteriorly through the dura. The spinal cord was kinked backwards by a hard swelling indenting the dura anteriorly, and was pale with some venous congestion. The dura and capsule of the prolapse were incised and soft, stringy disc tissue extruded. Complete removal, partly intra- and partly extra-dural, was effected.

Post-operative Course.-The patient developed retention of urine and impairment of pain, temperature, and light touch in the left leg. After 10 days the bladder recovered and power and sensation improved.

At one year after operation the patient can walk two miles with a stick and has returned to full work driving a van. Bladder control is practically normal. The original back pain has gone. Improvement still continues.

Case 2.-A man aged 44, a van driver, six months before admission developed a sensation of coldness and numbness on the outer side of the left leg below the knee, which had persisted but not extended. There had been weakness and stiffness of the right leg and similar changes in the left leg for six weeks, but no pain, no sphincter disturbance, and no spinal injury.

Neurological Examination.-There was moderate generalized weakness in the right leg and increased tone, with ankle and patella clonus. In the left leg power, tone, and coordination were normal.

Abdominal reflexes were absent. The right knee and ankle jerk were exaggerated. The left deep reflexes were normal. The plantar responses were extensor.

Sensory change was confined to diminution of pain sense on the outer side of the left leg from knee to ankle. All other modalities were normal.

Radiography._Arthritic lipping of the bodies of most thoracic vertebrae was seen, and spotty calcification in the anterior portion of the nucleus pulposus of the eighth-ninth disc with narrowing of the disc space.

Myelography (Cisternal).-Contrast was partially arrested just above the eighth-ninth disc.

Lumbar Puncture.-This showed normal manometrics. Protein was not recorded.

Operation.-Laminectomy of the seventh, eighth, and ninth vertebrae was performed. A firm swelling was felt through the dura at D.8 level. The cord was bulged backwards by a small tense prolapse from the eighth-ninth disc. Just to the right of the midline at the convexity of the bulge there was an area in the cord substance, $3 \mathrm{~mm}$. in diameter, which had a blue, translucent appearance. On incision of the prolapse soft, yellow tissue extruded. A complete intradural removal was effected.

Post-operative Course.-The patient had a complete flaccid paralysis of both legs. Below the eleventh thoracic dermatome all sensation was absent on the right but on the left pain and light touch could be felt although diminished. Urine and faeces were retained. Movement began to return in the feet in one month and there was slow recovery for 18 months after which his condition has remained stationary to the present time (11 years). He can stand, but with flexion of all joints, and can walk slowly with two sticks. He has dribbling incontinence and wears a rubber urinal all day and has a bottle in bed at night. The bowels act every fourth day with aperients. There is extreme spasticity of both legs with clonus and exaggerated reflexes and extensor plantar responses. Flexor spasms occur on the slightest 
stimulus. There is a level at the eleventh thoracic dermatome below which pin prick is impaired and thermal sensation is absent. Light touch is well appreciated. Joint sense is reduced in the toes.

Case 3.-A man aged 38, a business executive, nine months before admission, a few days after some heavy work in his garden, developed an aching sensation to the left of the midline of the back at about the dorsilumbar junction, and this ache had persisted. For two and a half months he had been unsteady on his feet and for the same time the right lower limb had been numb from the hip downwards, most evident on the lateral aspect of the leg and foot, with a tingling sensation in the toes of both feet. There was no sphincter disturbance.

Neurological Examination.--Slight weakness of both legs was detected predominating in the left and more marked peripherally, with increased tone, ankle and patella clonus on the left and patella clonus on the right.

The knee and ankle jerks were very brisk, particularly on the left, and the plantar responses were extensor.

Sensory change was confined to the right side. Below the twelfth thoracic dermatome there was impairment of pain and temperature with sparing of sacral segments. Light touch was normal. Vibration sense was absent at both malleoli. Joint and position sense was unaffected.

Radiography.-Calcification in the nucleus pulposus of both the eighth-ninth and ninth-tenth discs was seen, more extensive in the latter, with slight narrowing of the eighth-ninth disc.

Myelography.-Myelography showed an oval filling defect at the eighth-ninth disc level. In the lateral views a "double profile" (Fig. 8) was seen.

Lumbar Puncture.-Manometrics showed a partial block with a "sticky" rise and fall to $250 \mathrm{~mm} . \mathrm{H}_{2} \mathrm{O}$. The fluid contained 1 cell per c.mm. and $30 \mathrm{mg}$. of protein per $100 \mathrm{ml}$.

Operation.-Complete laminectomy of the eighth and ninth vertebrae was performed. A hard swelling was felt anteriorly. The spinal cord was displaced backwards by a spherical protrusion from the eighth-ninth disc lying mainly to the left of the midline. The spinal cord substance appeared normal. On incision through the dura and capsule soft, degenerate cartilage extruded. The harder rim was removed piecemeal.

Post-operative Course.-The legs were much weaker for a few days, but after that there was steady improvement. At three years after operation the patient can walk, run, dance, and dig as well as ever. Sensation is normal. His remaining symptoms are those of tightness in the calf muscles and some loss of potency.

Case 4.-A man aged 52, an insurance broker, two years before admission developed numbness in the left big toe which spread up the leg within a few months. Six months after the onset a similar change appeared in the right leg associated with weakness of this leg. After a further six months weakness started in the left leg. Both the motor and sensory loss progressed relentlessly so that at three months before admission a stage was reached where he was numb from the costal margin downwards and could take only a few faltering steps with support. Flexor spasms had been present for 12 months. Rectal control was normal, as was the initiation of micturition but he had difficulty in knowing when the bladder was empty. There had been no pain at any time. Six months after the onset of symptoms he had been investigated elsewhere when the cerebrospinal fluid and manometrics revealed no abnormality and a myelogram did not show a block.

Neurological Examination.--Some loss of power in the abdominal muscles with gross loss in both legs was perceived but a small range of movement was possible at all joints. Tone was increased without clonus.

The abdominal reflexes were absent. The knee and ankle jerks were exaggerated on the left, normal on the right. Plantar responses were both extensor.

There was a level at the sixth thoracic dermatome below which pain was considerably impaired and temperature sense was lost. From the sixth to the tenth dermatome the skin was hyperaesthetic to light touch and below this hypoaesthetic. These sensory changes extended down to cover the whole of the right leg but on the left leg there was relative sparing below the third lumbar dermatome. Position sense was reduced at the toes. Vibration sense was diminished at all bony points in the legs.

Radiography.-Mottled calcification was seen in the nucleus of the sixth-seventh disc.

Cisternal Myelogram.-This showed a complete block just above the area of calcification.

Lumbar Puncture.-A complete block was demonstrated. The fluid was yellow with increased protein (precise amount not recorded).

Operation.-Laminectomy of the fifth, sixth, and seventh thoracic vertebrae was performed. A hard swelling was palpable anteriorly. The spinal cord was angled backwards by a smooth disc prolapse occupying two-thirds of the diameter of the spinal canal. In the cord substance there was an area, $\frac{1}{2}$ in. long and $\frac{1}{4}$ in. wide, of a dark purple lying just to the left of the midline. On incision of the dura and capsule yellow degenerate disc tissue extruded. Its hard rim was completely removed intradurally. A few drops of yellow fluid were aspirated from the discolored area of the cord.

Post-operative Course.-The patient had almost complete motor and sensory paralysis, with retention. A few degrees of movement remained in the toes and there was patchy retention of light touch over both legs. Recovery in motor power started six weeks later and continued slowly so that he could walk with sticks at 11 months. Maximum recovery was attained four years after operation when he could walk with one stick for 15 minutes, could drive a car, and had control of the bowel and bladder although some urgency of micturition persisted. At six years a further deterio- 
ration set in, the legs became too weak to support him and he has remained bed-ridden to the present time (13 years after operation).

Case 5.-A man aged 62, an estate manager, three weeks before admission suddenly developed severe pain in the lumbar region radiating down both legs; it was particularly bad in the front of the thighs. He continued to work for five days when numbness appeared in the soles of both feet and spread rapidly up the legs and at the same time the legs became weak and his balance unsteady. There was no sphincter disturbance and no history of spinal injury.

Neurological Examination.-There was considerable weakness of the legs, more marked in the right, so that he was unable to lift them off the bed. One inch wasting of the right thigh and fibrillation in both calves, with general loss of tone, was also seen.

Knee jerks were diminished, ankle jerks absent, and plantar responses extensor.

Sensory change was confined to the antero-lateral aspects of both legs (fourth lumbar dermatome) where pain, temperature, and light touch were diminished. Joint sense was reduced in toes and ankles.

Radiography.-Considerable arthritic lipping of the lower six thoracic vertebrae was shown. There was dense calcification in the nucleus of the eighth-ninth disc with a thin plaque of calcification in the arachnoid, $1 \mathrm{~cm}$. long by $1 \mathrm{~mm}$. thick, at the level of the first lumbar vertebra.

Myelography.-A complete block at D.12/L.1 disc was seen.

Lumbar Puncture.-This showed an absolute manometric block. The fluid was yellow containing 7 cells per c.mm. and $175 \mathrm{mg}$. of protein per $100 \mathrm{ml}$.

Operation.-Laminectomy of the twelfth thoracic and first lumbar vertebrae was performed. The spinal cord was pushed over to the right by a large prolapse from the $12 / 1$ disc. The protrusion was exposed extradurally and, surprisingly, in view of the short history, was found to be of an extremely hard consistency and had to be cut away piecemeal. The calcified arachnoidal plaque was also removed.

Post-operative Course.-The patient had total motor and sensory paraplegia below the level of the second lumbar segment. He died four months later in another hospital from pyelonephritis without any recovery taking place. No necropsy was obtained.

Case 6.-A woman aged 44, a housewife, 14 months before admission found that her legs suddenly gave way and on picking herself up she realized that they were weak. The weakness progressed steadily after this, more marked in the right leg, and walking became difficult and she often fell. For six weeks before admission she could only go about by clinging on to furniture for support. At some time during these 14 months numbness had appeared in the legs but she could not give the precise time. She had no sphincter disturbance, no pain at any time, and no history of injury.

Neurological Examination.-There was considerable generalized weakness of both legs, more marked in the right, with increased tone and ankle and patella clonus.

The lower abdominal reflexes were absent, the knee and ankle jerks exaggerated, and plantar responses extensor.

There was a well-defined level at the eighth thoracic dermatome below which there was reduced sensation to pain and temperature, and from the eleventh dermatome downwards there was analgesia and thermoaesthesia. There was only vague and patchy loss to light touch. Joint sense was absent at the toes. Vibration sense was absent up to and including the iliac crests.

Radiography.-Granular calcification in the nucleus of the eighth-ninth disc without narrowing (Fig. 4) was seen. In the antero-posterior view a faint circular rim of calcification, $1.5 \mathrm{~cm}$. in diameter, was visible in the spinal canal overlying the calcified disc (Fig. 5). It could not be seen in the lateral view.

Myelography.-A circular filling defect, $1.5 \mathrm{~cm}$. in diameter, was seen at the calcified disc level and outlining the circular opacity.

Lumbar Puncture.-A complete manometric block was shown. The fluid was clear, containing 2 cells per c.mm. and $95 \mathrm{mg}$. of protein per $100 \mathrm{ml}$.

Operation.-Laminectomy o the eighth and ninth thoracic vertebrae was performed. A hard swelling was felt anteriorly in the dural sac. The cord was kinked backwards by a prolapse from the eighth-ninth disc. Owing to the firm consistency of the prolapse it was not removed. Two ligamenta denticulata were divided and the dura left open.

Post-operative Course.-There was total transection below the eighth thoracic segment. At six months a few degrees of movement had returned in the left ankle and knee and in the right ankle with a little recovery of pain sense below the right knee with hyperpathia. The legs were extremely spastic with frequent flexor spasms. The patient had recurring attacks of urinary sepsis and developed bed sores. She eventually died nine months after operation.

At necropsy the prolapse, cord, and dura were removed in one piece and sectioned (Fig. 9).

Case 7.-A woman aged 63, a housewife, 10 years before admission twisted her spine suddenly and the following day she found she was unsteady on her feet tending to veer to the left. A week later on getting into a bath she observed that she could not appreciate temperature in the skin below the knee on the right, and urgency of micturition developed. Two years later both legs became stiff and weak, more marked in the right, but the bladder symptoms had cleared up. During the last six years preceding admission the weakness and stiffness progressed so that she could get about only by holding on to the furniture, and both legs felt numb. For one year the legs were much weaker and she could 
just stand with support. Flexor spasms occurred frequently. Urgency of micturition had reappeared with occasional incontinence. There had been no pain at any time.

Neurological Examination.--There was extreme weakness of both legs with a small range of movement retained at all joints, and gross spasticity with ankle and patella clonus.

The abdominal reflexes were absent, the knee and ankle jerks exaggerated, with bilateral extensor plantar responses.

Sensation was difficult to define, but repeated testing indicated some reduction of pain, temperature, and light touch below the second lumbar dermatome on the right and the third dermatome on the left. Vibration sense was absent in the tibiae and patellae. Joint sense was unaffected.

Radiography.-There was gross arthritic lipping of all thoracic vertebrae. No calcification was seen.

Myelography.-Myelograms showed a partial block at the level of the tenth-eleventh intervertebral disc, with a convex lower border.

Lumbar Puncture.-This demonstrated a complete manometric block. The fluid was clear, containing 3 cells per c.mm. and $150 \mathrm{mg}$. of protein per $100 \mathrm{ml}$.

Operation.-Laminectomy of the tenth, eleventh, and twelfth vertebrae was performed. A hard lump was palpable. The cord was bulged backwards and was of paper thinness and for almost a centimetre of its length had a translucent blue discoloration. The prolapse was an extremely hard bar extending across the spinal canal containing a small amount of soft cartilage set between bony spurs. The ligamenta denticulata were divided above and below but no attempt was made to remove the disc prolapse.

Post-operative Course.-Paraplegia below the first lumbar spinal segment was complete. It is now four years since operation and there has been no recovery in power or sensation. There is some return of tone in the legs and the patient is able to get about in callipers and crutches. By emptying the bladder every three hours she remains dry.

Case 8.-A man aged 54, a charge hand, 11 weeks before admission suddenly developed severe pain in the lumbar region which radiated down his legs both back and front to the feet. Sharp exacerbations occurred on coughing, sneezing, and straining. He remained in bed for six days and then on getting up found his legs were very weak. This weakness progressed rapidly so that within another few days his legs would not support him. At the same time a burning sensation appeared in the lateral toes of both feet which spread to involve the front of the legs below the knees and within a few days was replaced by numbness. Urgency of micturition appeared at the start of symptoms but cleared up within a few weeks. He was admitted to another hospital five weeks after the onset where after an initial slight improvement his condition remained stationary.
Neurological Examination.-There was considerable generalized loss of power in both legs, more marked in the right. Tone was increased with ankle clonus.

The abdominal reflexes were absent, the knee and ankle jerks exaggerated, and plantar responses extensor.

Cutaneous sensory change was confined to an area on the anterior aspects of both shins (corresponding to the fourth lumbar dermatome) where there was reduction of pain, temperature, and light touch. Position sense was impaired in the toes. Vibration sense was reduced in the left tibia.

He could walk without support but unsteadily, on a broad, shuffling base, with considerable pain.

Radiography.-Gross arthritic lipping of most of the thoracic and all the lumbar vertebrae was seen, but no calcification.

Myelography.-Myelograms showed complete block at the level of the intervertebral disc between D12/L1 vertebrae. The obstruction was outlined from above and below and was found to be $1.5 \mathrm{~cm}$. long and to have a rounded outline.

Lumbar Puncture.-Almost complete manometric block was shown. The fluid contained 2 cells per c.mm. and $200 \mathrm{mg}$. of protein per $100 \mathrm{ml}$.

Operation.-Laminectomy of the twelfth thoracic and first lumbar vertebrae was performed. A firm knob was felt anteriorly in the theca. The cord was bulged backwards and was pinker than usual. Anterior to it was a large and extremely hard prolapse from the 12/1 disc. Its hardness was surprising in view of the short history. No attempt was made to remove it and the patient was left with a decompression.

Post-operative Course.-The paraplegia was made worse and retention of urine developed. After 10 days improvement started and within a few weeks he regained his pre-operative level. The cutaneous sensory change cleared up.

Two and a half years after operation he can get about his house and garden and can walk distances up to 200 yards. He can stand for periods up to half an hour before aching in the legs becomes severe. Sphincter control is normal. The operation seems to have arrested the progress of the condition and there has been a little improvement in movement compared with his pre-operative state.

Case 9.-A man aged 61, a labourer, 13 days before admission, while putting on his overcoat, suddenly developed severe pain in the midline of the lumbar region and at the same time his legs became weak. He retired to bed and on attempting to get up two days later he found his legs would not support him. He had observed no sensory or sphincter disturbance, and there was no history of spinal injury.

Neurological Examination.-There was generalized weakness of both legs, more marked in the right, and increased tone with patella clonus. Coordination was grossly impaired.

Both knee jerks were exaggerated, the ankle jerks brisk. Plantar responses were extensor. 
There was vague loss of sensation to pin prick below mid-thighs which cleared up within a few days. Temperature and light touch were unaffected. Position sense was considerably reduced at the toes and ankles and vibration sense was absent in the tibiae.

Radiography.-There was arthritic lipping of the lower thoracic and all the lumbar vertebrae, but no calcification or disc narrowing.

Myelography.-A circular lesion causing a complete block was outlined from above and below over the tenth-eleventh intervertebral disc (Fig. 6). In the lateral view a suggestion of a "double profile" could be seen.

Lumbar Puncture.-A partial block was shown. The fluid contained 4 cells per c.mm. and $100 \mathrm{mg}$. of protein per $100 \mathrm{ml}$.

Operation.-Laminectomy of the tenth, eleventh, and twelfth thoracic vertebrae was performed. A firm mass could be felt anteriorly in the theca. The cord was kinked backwards and a little swollen but not discoloured. A tense swelling could be seen arising from the 10/11 disc lying to the left of the midline. It was approached extradurally and found to be the size of a pea and composed of soft degenerate disc tissue identical with the common lumbar protrusions. It was removed completely.

Post-operative Course.-After a transient exacerbation of signs power increased considerably in the legs with disappearance of spasticity and clonus and he could walk with support. Joint sense returned to normal within a fortnight. Now, 10 months after operation, he is able to walk any distance with one stick and his only complaint is of a little unsteadiness on his feet. There is no pain or sensory disturbance and sphincter control is normal.

Case 10.-A man aged 44, an engineer, five months before admission developed difficulty in starting micturition and had to strain to empty his bladder. This symptom cleared up in a fortnight. Two weeks later stiffness and weakness of the left leg appeared and after a further month the right leg was similarly affected. The weakness in both legs progressed steadily so that for the month before admission he had been unable to walk and had also become incontinent of urine and faeces. A sensation of coldness behind both knees appeared at the inception of his symptoms and remained stationary until the last few weeks when numbness of the skin below the umbilicus was noticed and which rapidly spread down to involve both legs. For one week there had been frequent flexor spasms. There was no complaint of pain at any time.

Neurological Examination.-Some weakness of the lower abdominal muscles with gross reduction of power in both legs was perceived so that the patient was unable to lift them off the bed, but a small range of movement was retained at all joints. Tone was increased with clonus at the left ankle. The lower abdominal reflexes were absent, the knee and ankle jerks exaggerated, the plantar responses extensor.

There was a level at the eleventh thoracic dermatome on the right and the twelfth on the left below which pain, temperature, and light touch were impaired but not lost. Position sense was absent at the toes, ankles, and knees, and reduced at the hip joints. Vibration sense was lost below the third lumbar spinous process.

Radiography.-Arthritic lipping of the lower three thoracic vertebrae was visible. Calcification of the nucleus pulposus was present in the four intervertebral discs between the $8 / 9,9 / 10,10 / 11$, and $11 / 12$ vertebrae (Fig. 2).

Myelography.-There was no block discernible on running the contrast up to the cervical region, but in the reverse direction there was a transient arrest at the 6.7 disc and again at the 8/9.

Lumbar Puncture.-Partial block was shown. The cerebrospinal fluid was clear and contained 2 cells per c. $\mathrm{mm}$. and $20 \mathrm{mg}$. of protein per $100 \mathrm{ml}$.

Operation.-Laminectomy of the seventh to the tenth vertebrae inclusive was performed to expose both levels which the myelogram had shown to be abnormal. The protrusion was found at the lower, 9/10 level (there was no abnormality discovered at the 6/7 disc). The cord was paler than normal and had fewer blood vessels on its surface. It was kinked back by a protrusion the size of a pea lying slightly to the left of the midline. The centre of the prolapse was soft but its wall was very hard and calcified, and it appeared that the protrusion had been present for a much longer time than the symptoms suggested. Its contents were removed and then the rim excised piecemeal with a small scoop.

Post-operative Course.-Transient worsening of physical signs for a few days was followed by steady if slow improvement. Within two weeks the patient could lift his legs off the bed and had regained bladder control. The sensory and reflex changes persisted. Two and a half years after operation he can walk up to 500 yards with two sticks and can climb stairs slowly. He has recently returned to sedentary work. He still has some urgency of micturition.

Case 11.-A man aged 45, a research chemist, whose clinical features have been described on a previous page.

Radiology.-Calcification was present in the nucleus pulposus of the ninth-tenth disc, without any narrowing (Fig. 3).

Myelography.-Myelograms showed an oval filling defect at the level of the calcification measuring $1 \frac{1}{2} \mathrm{~cm}$. in diameter (Fig. 7).

Lumbar Puncture.-Manometrics were normal. The cerebrospinal fluid contained 4 cells per c.mm. and 50 $\mathrm{mg}$. of protein per $100 \mathrm{ml}$.

Operation.-In view of the discrepancy between the clinical and radiological levels it was thought there might be two lesions and that both should be explored. 
The upper level was exposed first and revealed no abnormality. A laminectomy of the ninth and tenth vertebrae was performed and a firm swelling could be felt in the dural sac On opening the theca the cord was seen to be displaced backwards by a prolapsed disc. The protrusion arose by a narrow neck and then expanded into a spherical mass about $1 \frac{1}{2} \mathrm{~cm}$. across with the dura and cord stretched over its surface. There was no discoloration of the cord substance. The rim of the disc was hard and partly calcified but its contents were soft, degenerate cartilage. As a result of the intimate relationship to the cord it was extremely difficult to remove all the calcified rim and its right-hand margin had to be left in situ.

Post-operative Course.-Physical signs were made considerably worse and the bladder required tidal drainage. Improvement started after 10 days. By the time of discharge from hospital five weeks later power had improved so that the patient could walk without assistance although unsteadily. By four months after operation he was walking normally.

Three and a half years after operation he walks, runs, swims, and drives a car. All modalities of sensation are normal except for subjective numbness of the feet. The right knee jerk is still brisk but plantar responses are flexor. His only complaint is that of a sensation of tightness in the calf muscles.

\section{Summary}

Attention is drawn to the serious damage inflicted on the spinal cord by central thoracic disc protrusions. Eleven cases are described and it is shown that this type of prolapse is confined to the lower nine disc spaces without any particular level predominating. It is commoner in men of middle and late adult life and has little relationship to trauma.

The clinical features are not characteristic and are those of a fairly rapidly progressive spinal compression, so that in eight of the patients a severe neurological disability leading to operation was present within seven months from the onset of symptoms. Three cases presented with incomplete Brown-Séquard syndromes. Pain was an infrequent symptom. Sphincter disturbance occurred late and was present in less than half the cases.

Five patients showed a manometric spinal block with high protein but the important feature was the number of patients with only a slight rise of protein or little evidence of block. $X$-ray changes formed the important diagnostic guide. Eight showed calcification of the nucleus pulposus. The typical myelographic appearance was an oval filling defect.

The dangers associated with visible degenerative changes in the cord are emphasized.

The pathological basis of interference with cord function produced by the small protrusions is discussed.

Operation results are reviewed. Three patients developed total transections post-operatively and two of them died. Two other patients were made worse by surgery and made slow, incomplete recoveries. Six patients did well, five of them returned to work, and in three the improvement was of a grade similar to that following removal of benign spinal neoplasms such as meningiomata or neurofibromata. Some details of surgical technique are stressed.

It is a pleasure to express my indebtedness to my senior colleague Mr. Wylie McKissock for permission to include six of his patients in this series; to Professor T. Crawford for the preparation of the necropsy specimen in Case 6 and the photomicrographs of the sections, and to Dr. James Bull for many of the radiographs and myelograms.

\section{REFERENCES}

Allen, K. Lewer (1952). Journal of Neurology, Neurosurgery and Psychiatry, 15, 20.

Bradford, F. K., and Spurling, R. G. (1945). The Intervertebral Disc, 2nd ed. Springfield, Ill.

Elsberg, C. A. (1931). Bull. neurol. Inst. N.Y., I, 350.

Elsberg, C. A. (1931). Bull. neurol. Inst
Hawk, W. A. (1936). Brain, 59, 204.

Hawk, W. A. (1936). Brain, 59, 204.

Kahn, E. A. (1947). J. Neurosurg., 4, 191.

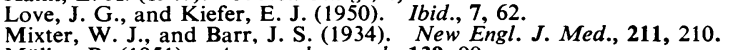

Müller, R. (1951). Acta med., scand., 139, 99.

Stookey, B. (1928). Arch. Neurol. Psychiat., Chicago, 20, 275.

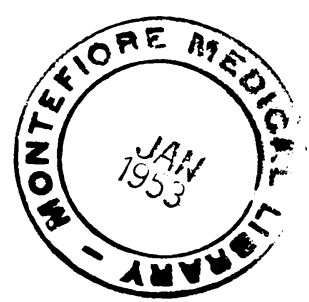

